\title{
1RXS J232953.9+062814: A POSSIBLE PROGENITOR OF AM CVn STARS
}

\author{
M. Uemura ${ }^{1}$ \\ RESUMEN
}

Hemos descubierto que la variable cataclísmica rica en hidrógeno 1RXS J232953.9 + 062814 es una nova enana de tipo SU UMa con un período de superjoroba de $66.774 \pm 0.010 \mathrm{~min}$. Se ha determinado un período orbital fotométrico igual a $64.184 \pm 0.003 \mathrm{~s} \mathrm{~min}$, el cual se encuentra por debajo del período mínimo. A pesar de que el escenario evolutivo estándar de variables cataclísmicas predice menores tasas de transferencia de masa en sistemas con períodos orbitales más cortos, el corto tiempo de recurrencia de las explosiones y su brillante magnitud aparente indican que este objeto posee una tasa relativamente alta de transferencia de masa. Junto con el sistema análogo V485 Cen, estos objetos establecen la primera subpoblación de variables cataclísmicas ricas en hidrógeno con períodos inferiores al período mínimo. En cuanto a su estado evolutivo proponemos que se trata de progenitoras de estrellas AM CVn en regímenes evolutivos donde los sistemas poseen una estrella secundaria evolucionada con un núcleo en el que se ha agotàdo el hidrógeno.

\section{ABSTRACT}

We revealed that the hydrogen-rich cataclysmic variable 1RXS J232953.9+062814 is an SU UMa-type dwarf nova with a superbump period of $66.774 \pm 0.010 \mathrm{~min}$. A photometric orbital period is determined to be $64.184 \pm$ $0.003 \mathrm{~min}$, which is below the period minimum. Although the standard evolutionary scenario of cataclysmic variables predicts lower mass-transfer rates in systems with shorter orbital periods, its short recurrence time of outbursts and bright apparent magnitude indicate that this object has a relatively high mass-transfer rate. With the analogous system V485 Cen, these objects establish the first subpopulation in hydrogen-rich cataclysmic variables below the period minimum. Concerning the evolutionary status of them, we propose that they are progenitors of AM CVn stars on evolutionary courses in which systems have an evolved secondary star with a hydrogen-exhausted core.

Key Words: ACCRETION, ACCRETION DISKS - BINARIES: CLOSE

\section{INTRODUCTION}

1RXS J232953.9+062814 (= EI Psc) was discovered as an X-ray source with the ROSAT (Voges et al. 1996). Hu et al. (1998) reported an identification with an optical source of $V=15.7$ and light curves described by two distinct states; one is a faint state in which the optical spectrum is dominated by hydrogen emission lines, indicating that this object is a hydrogen-rich CV. A noteworthy feature during this state is $\mathrm{TiO}$ absorption bands typical of M-type stars. The other state is a bright one in which the hydrogen lines appear in absorption. Based on these observations, this object was classified as a dwarf nova (DN).

We performed detailed photometric observations of an outburst in 2001 November 3. Our observation revealed that this object is an SU UMa-type DN, which has an ultrashort orbital period for hydrogenrich CVs (Uemura et al. 2002a; Uemura et al. 2002b). In this paper, we report on observational properties and an evolutionary scenario for this peculiar object.

\footnotetext{
${ }^{1}$ Department of Astronomy, Kyoto University, Japan.
}

\section{OUTBURST PROPERTIES}

Figure la shows the light curve during this outburst. Our observation detected superhumps during a plateau phase of the outburst. We show their typical light curves in figures $1 \mathrm{~b}$ and $c$. The best candidate of the period was calculated to be $66.774 \pm 0.010 \mathrm{~min}$. During the quiescent phase, the object exhibited ellipsoidal modulations, as can be seen in figure 1d (Thorstensen et al. 2002). Using quiescent light curves, our period analysis yielded an orbital period of $64.210 \pm 0.023 \mathrm{~min}$. The superhump period excess is calculated to be $4.036 \pm 0.015 \%$. The object, hence, has an orbital period shorter than the well-known period minimum although it has a hydrogen-rich spectrum.

We estimated its quiescent absolute magnitude to be $+7.8<M_{V}<+8.8$ based on the $P_{\text {orb }}-M_{V \text {. peak }}$ relationship and proper motions, respectively (Lemura et al. 2002a). The estimated quiescent brightness is surprisingly high, as can be seen from figure 2. The object definitely has a high masis-transfer rate, which contradicts the standard evolutionary 

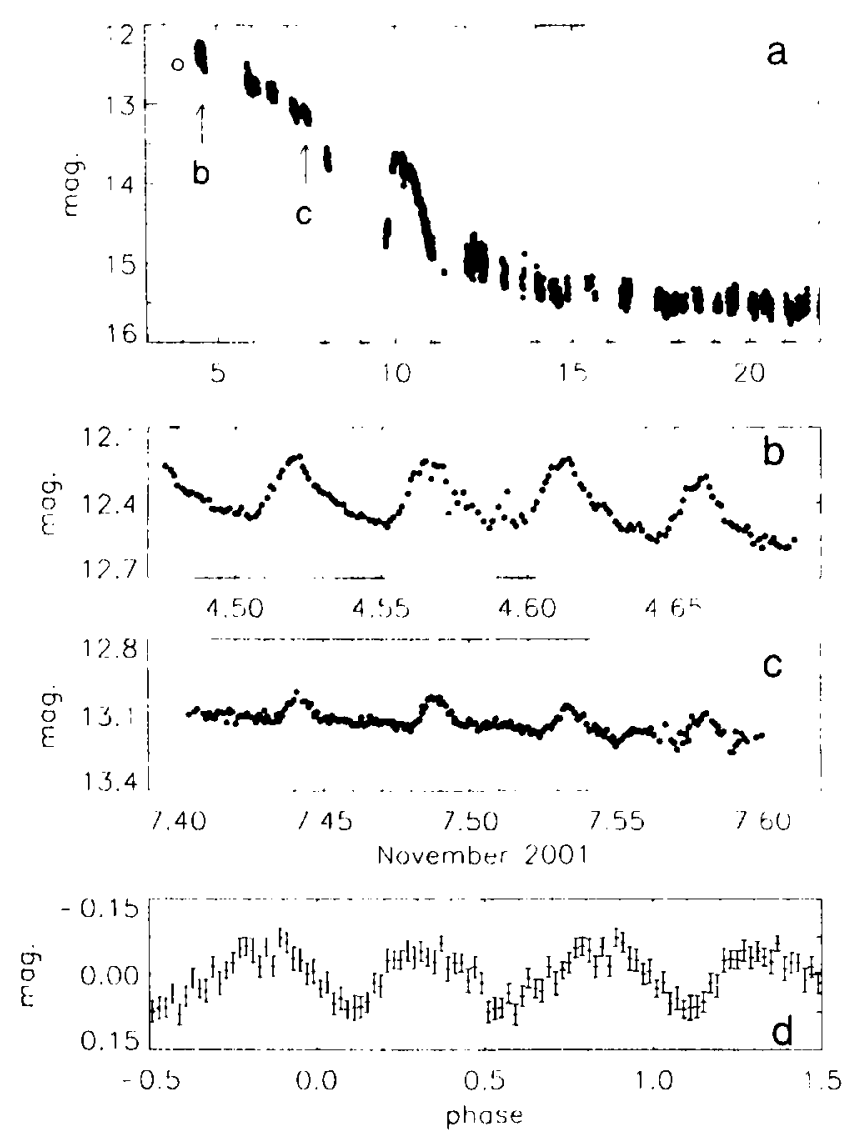

Fig. 1. Light curve of IR Sis . 12:32953.9+06i281.1 during the outburst in 2001 Vesenuber. (a): The whole light curve of the outburst. (b) and (c): Superhumps on November 1 and 7 , respectively (al): Average quiescent light curve. We folded the light alrves wit the period of 6.t.18.t min. The alsoseissa and ordinate denote the phase in this period and the relation magnitude, respectively (from Ucumaria al. 20):a).

scenario, as depicted in figure 2- The superbump period excess is a function of the mass ratio of systems. The large superhump exeess of this object indientes an unexpectedly large mass ratio compared with ordinary short-period sistems. The empirical relation yields $q=0.19 \pm 0.02$ (Pattersom 2001 ). These arguments imply the presence of at matsise secondary. which probably leads to the high milss-transfer rate.

\section{EV(OLITIONART STATUS}

The ordinary evolutionary secuence of (lis has been considered with secondary stars near mainsequence. This sequence makes the period minimum around $70 \mathrm{~min}$ and is difficult to explain the presence of this object. We propose that this object has an evolved secondary star which hats a hydrogenexhausted core (also see Thorstensen et al. 2(0)2). According to Podsiadlowski of al. (2003). such sistems haw a shorter period minimum and. further-

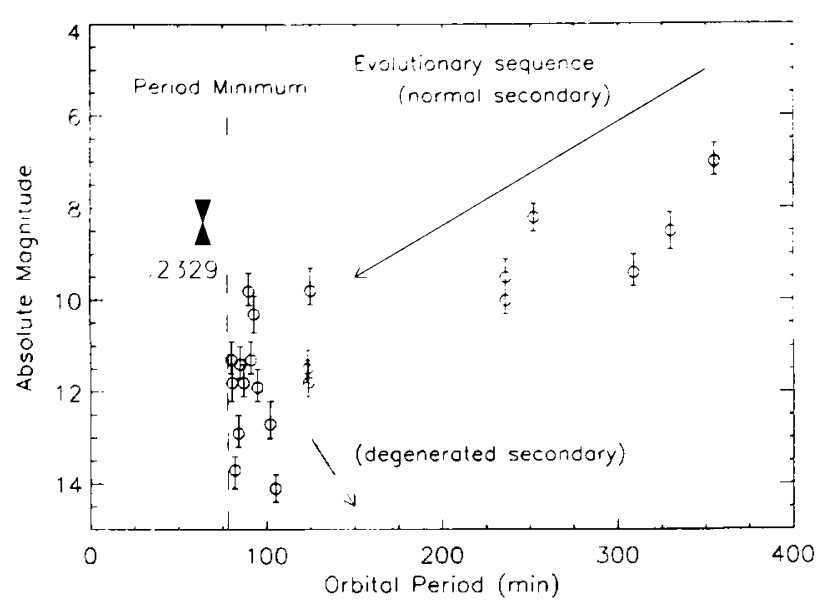

Fig. 2. Absolute magnitude of $\mathrm{CVs}$ as a function of the orbital periorl. Wo show the lower and upper limit of the yuicsc'ntl magnitude of 1 RXS J232953.9+062814 as filled triangles and indicater by 'J2329'. The open circles denote DNo listed in Sproats et al. (1996). The arrows are schematic evolutionary sequences for ordinary CVs. The vertical dotted line shows the observed period minimum (80 min) (from Uemura ct al. 2002a).

more, have moro luminous (and massive) secondary stars around their period minimum. They predicted that, before the period minimum, such CVs still have much hydrogen in their surface, which is consistent with the hydrogen-rich spectrum of this object.

This scenario predicts that the binary system shrinks with time until the secondary star degeneratc's. At its period minimum, the surface abundance of hydrogen will significantly decrease compared with the current state. The object, then, possibly appears to be an AM CVn star after the period minimum. This is just the CV channel proposed as an evolutionary sequence of AM CVn stars by Podsiadlowski et al. (2003). The discovery of a high $\dot{M}$ and a luminous secondiary star of 1RXS J232953.9+062814 provides observational evidence for the CV channel. Wi propose that $185 \mathrm{C}$ Cen in a twin of this object.

\section{REFERENCES}

Hu, J.. Wri. J., Xu. D., Cao, L.. \& Dong, X. 1998, Ann. Shanghai Obs., Acad. Sin., 19, 235

Patterson, J. 2001, PASP, 113. 736

Podsiadlowski, P.. Han, Z. \& Rappaport, S. 2003, MNR.AS. 340.1214

Sproats. L. N. Howell. S. B., \& Mason. K. O. 1996, MNR.AS. 2N:2. 1:211

Thorstensen. J. R.. Fenton. II: H., Patterson. J. O., Kemp, J.. Firajci. T.. \& Baraffe. I. 2002, ApJ, 567, L49

Lemura. M. et al. 2002a. PASJ. 54. L15

Lemura, M. et al. 2002b. PASJ. 54. 599

Viges. II et al. 1996. IAI' Circ. 6420 